\title{
References
}

$1 \quad$ Young T, Peppard PE, Taheri S. Excess weight and sleep-disordered breathing. J Appl Physiol 2005; 99: 1592-1599.

2 Ferrannini E, Natali A, Bell P, et al. Insulin resistance and hypersecretion in obesity. European Group for the Study of Insulin Resistance (EGIR). J Clin Investig 1997; 100: 1166-1173.

3 Tasali E, Mokhlesi B, Van, et al. Obstructive sleep apnea and type 2 diabetes: interacting epidemics. Chest 2008; 133: 496-506.

4 Berry RB, Budhiraja R, Gottlieb DJ, et al. Rules for scoring respiratory events in sleep: update of the 2007 AASM Manual for the Scoring of Sleep and Associated Events. Deliberations of the Sleep Apnea Definitions Task Force of the American Academy of Sleep Medicine. J Clin Sleep Med 2012; 8: 597-619.

5 Pei D, Jones CN, Bhargava R, et al. Evaluation of octreotide to assess insulin-mediated glucose disposal by the insulin suppression test. Diabetologia 1994; 37: 843-845.

6 Facchini FS, Hua N, Abbasi F, et al. Insulin resistance as a predictor of age-related diseases. J Clin Endocrinol Metab 2001; 86: 3574-3578.

7 Punjabi NM, Beamer BA. Alterations in glucose disposal in sleep-disordered breathing. Am J Respir Crit Care Med 2009; 179: 235-240.

8 Punjabi NM, Sorkin JD, Katzel LI, et al. Sleep-disordered breathing and insulin resistance in middle-aged and overweight men. Am J Respir Crit Care Med 2002; 165: 677-682.

9 Kapsimalis F, Kryger MH. Gender and obstructive sleep apnea syndrome, part 1: Clinical features. Sleep 2002; 25: $412-419$.

10 Shin MK, Yao Q, Jun JC, et al. Carotid body denervation prevents fasting hyperglycemia during chronic intermittent hypoxia. J Appl Physiol (1985) 2014; 117: 765-776.

11 Deng X, Gu W, Li Y, et al. Age-group-specific associations between the severity of obstructive sleep apnea and relevant risk factors in male and female patients. PLoS One 2014; 9: e107380.

12 Gabbay IE, Gabbay U, Lavie P. Obesity plays an independent worsening modifying effect on nocturnal hypoxia in obstructive sleep apnea. Sleep Med 2012; 13: 524-528.

13 Peppard PE, Ward NR, Morrell MJ. The impact of obesity on oxygen desaturation during sleep-disordered breathing. Am J Respir Crit Care Med 2009; 180: 788-793.

14 Levendowski DJ, Zack N, Rao S, et al. Assessment of the test-retest reliability of laboratory polysomnography. Sleep Breath 2009; 13: 163-167.

15 Balkau B, Vol S, Loko S, et al. High baseline insulin levels associated with 6-year incident observed sleep apnea. Diabetes Care 2010; 33: 1044-1049.

\section{Spontaneous pneumothorax can be associated with TGFBR2 mutation}

To the Editor:

Primary pneumothorax affects $0.01 \%$ of the population. $10 \%$ of cases have a family history of pneumothorax but in the majority, a definitive genetic diagnosis is not made. We report a 26-year-old, white British woman who presented with left apical pneumothorax (figure 1a). Previously, she had migraines, multiple stress fractures in her right foot, myopia, easy bruising, lumbar scoliosis and spontaneous dislocation of the right patella. She had no previous history of pneumothoraces or any other respiratory problems, and had never smoked.

On examination, she was hypermobile (Beighton score 7/9), and had facial milia, translucent hyperextensible skin, striae over her back, chest wall asymmetry, bilateral varicose veins and pes planus. Her uvula was bifid (figure 1b), she had a high arched palate with dental crowding and her arm span/ height ratio was increased (1.14). In the ophthalmology clinic, lattice dystrophy (weakness in the peripheral retina predisposing to retinal detachment) was identified with no ocular features of Marfan syndrome. The patient's thoracic computed tomography (CT) revealed apical blebs, and her echocardiogram and CT showed aortic root dilatation $(3.54 \mathrm{~cm}$, Z-score $>2$ ) (figure $1 \mathrm{c}$ and d). Her 59 -year-old mother, who had not suffered pneumothoraces, was reviewed and found to have mild features of a connective tissue disorder: skin hyperextensibility, joint hypermobility with a Beighton scale score of 5/9, a high-arched palate, mild thoracic kyphosis, easy bruising, recurrent left shoulder dislocation, hiatus hernia, stress incontinence and stress fractures of the left foot.

These findings led to the clinical diagnosis of Loeys-Dietz syndrome (LDS), an autosomal dominant disorder affecting the transforming growth factor (TGF)- $\beta$ signalling pathway [1]. LDS (types I-V: Online Mendelian Inheritance in Man numbers 609192, 610168, 613795, 614816 and 615582, respectively) is 
characterised by vascular findings (cerebral, thoracic and abdominal arterial aneurysms/dissections) and skeletal manifestations (pectus excavatum or pectus carinatum, scoliosis, joint laxity, arachnodactyly, and talipes equinovarus). Approximately $75 \%$ of affected individuals have LDS type I with craniofacial manifestations (hypertelorism, bifid uvula/cleft palate and craniosynostosis); approximately 25\% have LDS type II with systemic manifestations of LDSI but minimal or absent craniofacial features. LDSI and LDSII form a clinical continuum. The natural history of LDS is characterised by aggressive arterial aneurysms (mean age at death 26.1 years) and a high incidence of pregnancy-related complications, including death and uterine rupture. The diagnosis of LDS is based on characteristic clinical findings in the proband and family members and molecular genetic testing of TGFBR1 (TGF- $\beta$ receptor (TGF $\beta R$ I), TGFBR2 (TGFBRII), SMAD3, TGFB2 (TGFß2) and TGFB3 (TGFß3).

Other connective tissue disorders such as Marfan syndrome were not considered likely, especially with the clinical findings of facial milia and bifid uvula, as these are specific to LDS. Her TGFBR1 and TGFBR2 genes were sequenced from leukocyte-derived DNA and she was found to be heterozygous for a novel missense variant of the TGFBR2 gene (c.1262C>A; p.Thr421Asn; reference sequence NM_003242.5) (figure 1e). Subsequent testing found her mother to be a low-level mosaic for this variant.

The pathogenicity of novel missense variants of disease-associated genes is often uncertain. The threonine at position 421 is a highly conserved residue within the protein kinase domain of TGFßRII. In silico analysis of the identified variant using SIFT and Polyphen suggested pathogenicity, with SIFT predicting the change to affect protein function and Polyphen predicting the change to be damaging. This variant was listed on neither the Human Gene Mutation Database nor the Exome Aggregation Consortium database.

There is no crystal structure available for the TGF $\beta$ RII protein; however, based on a structure of the homologous activin receptor (ActR)IIB (47.57\% identity within their kinase domains: TGFßRII residues 244-544 and ActRIIB residues 190-480), we assessed the interactions in this highly conserved region. This predicted the new mutation would disrupt an intramolecular hydrogen bond stabilising the highly conserved kinase activation loop and so affect activity (figure 1f). Effects upon folding could not be excluded by this approach though we considered this unlikely. We therefore assessed the folding and function of the new variant. Human embryonic kidney (HEK)293T cells were transiently transfected with expression vectors encoding TGFßRII proteins: wild type (WT), the new T421N mutant and a known kinase-dead mutant, R528C [2]. Protein lysates were either left untreated, or digested with endoglycosidase H, which digests immature glycans on proteins within the endoplasmic reticulum, or peptide $N$-glycosidase, which removes all $N$-linked glycans regardless of their complexity. Lysates were then subjected to SDS-PAGE, transferred to nitrocellulose and immunoblotted for TGFßRII. The T421N variant was well expressed in cultured mammalian cells and, similar to the known inactive R528C mutant, displayed a mature glycosylation pattern suggesting it was well folded and had exited the endoplasmic reticulum (figure $1 \mathrm{~g}$ ).

It is known that mutants of TGFßRII exist that lack normal kinase activity but traffic normally [2]. We therefore purified TGFßRII WT protein, the T421N variant and the kinase-deficient variant R528C. HEK293T cells were transiently transfected with expression vectors encoding TGFßRII proteins tagged on their C-termini with FLAG: WT, T421N, R528C and a weak hypomorphic variant, V387M (our unpublished observation). Cells were lysed and FLAG-tagged proteins purified by immunoprecipitation. After elution from the antibody using FLAG peptide, one third of the material was incubated with $\left[\gamma^{32} \mathrm{P}\right]$-ATP for $30 \mathrm{~min}$ at $30^{\circ} \mathrm{C}$ then separated by SDS-PAGE and exposed to a phosphorimager plate. As expected, the positive control WT TGFBRII autophosphorylated strongly while the negative control R528C did not (upper panel of figure $1 \mathrm{~h}$ ). The novel T421N mutant also showed impaired autophosphorylation, indicating it to be pathogenic and confirming the clinical diagnosis of LDS. As radiolabelling does not lend itself well to clinical laboratory practice, we also examined unlabelled proteins by Phos-tag gel followed by immunoblotting. This technique separates proteins both by their size and by degree of phosphorylation [3]. Once again, the positive and negative controls separated well, and the T421N mutant showed a clear reduction of autophosphorylation (lower panel in figure $1 \mathrm{~h}$ ).

The precise mechanism by which haploinsufficiency for TGFBR2 leads to disease is unclear but in mice, deficiency of Tgfbr2 in cranial neural crest cells leads to elevated expression of TGF 32 and TGFßRIII [4]. This increases Smad-independent downstream signalling leading to defective proliferation of palatal mesenchyme and may account for the craniofacial defects observed in LDS.

Although one review has noted pneumothoraces in cases of known LDS [5], to our knowledge, this is the first documented case of LDS to present with pneumothorax. We have confirmed the causative mutation to be a kinase-dead allele of TGFBR2 by developing both radioactive and nonradioactive assays for TGF $\beta$ RII autokinase activity. As the identification of multiple variants, either through targeted gene analysis or through panel testing of large numbers of genes, becomes routine, such in vitro techniques for the functional characterisation and validation of putative disease-causing mutations will be increasingly important. LDS should be considered as a monogenic cause of pneumothorax in addition to the more 

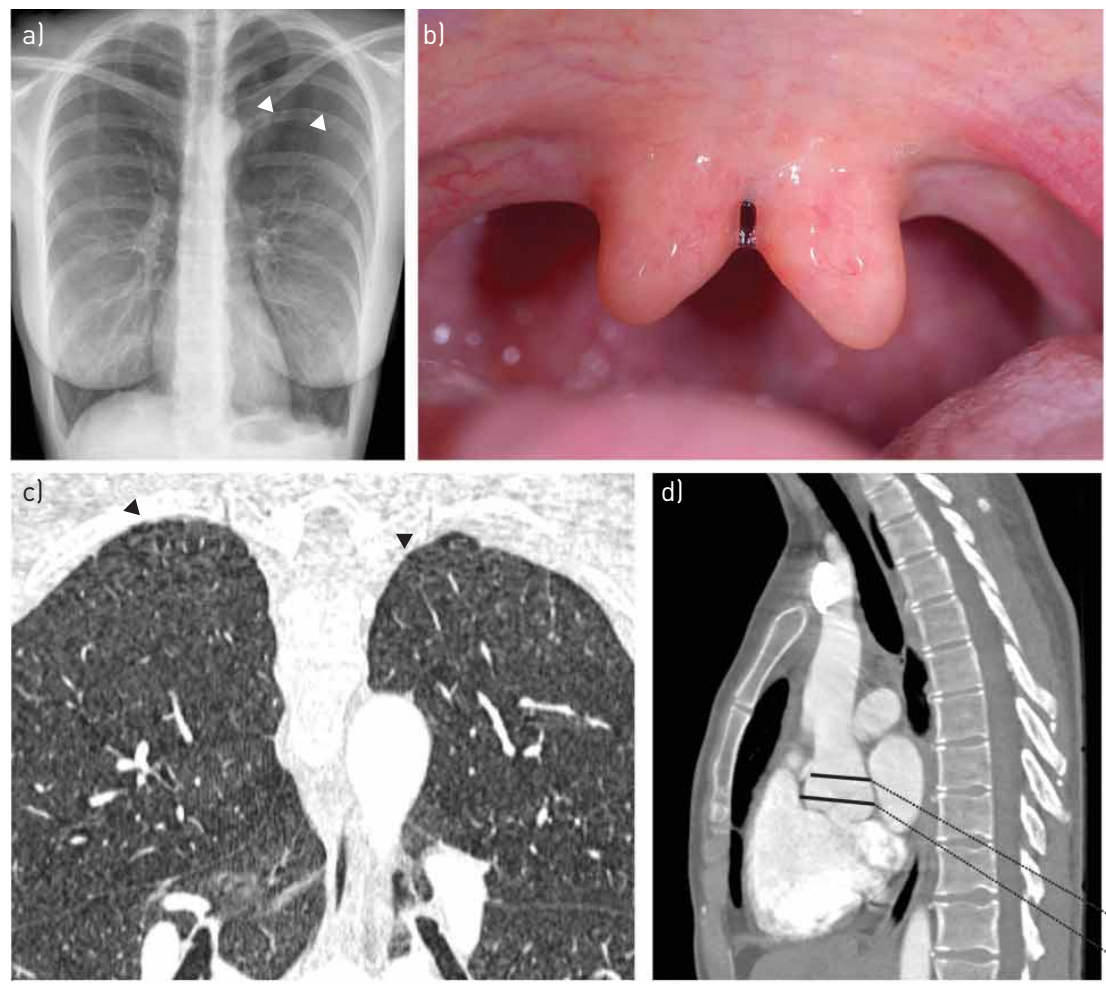

$2.93 \mathrm{~cm}$

$3.54 \mathrm{~cm}$
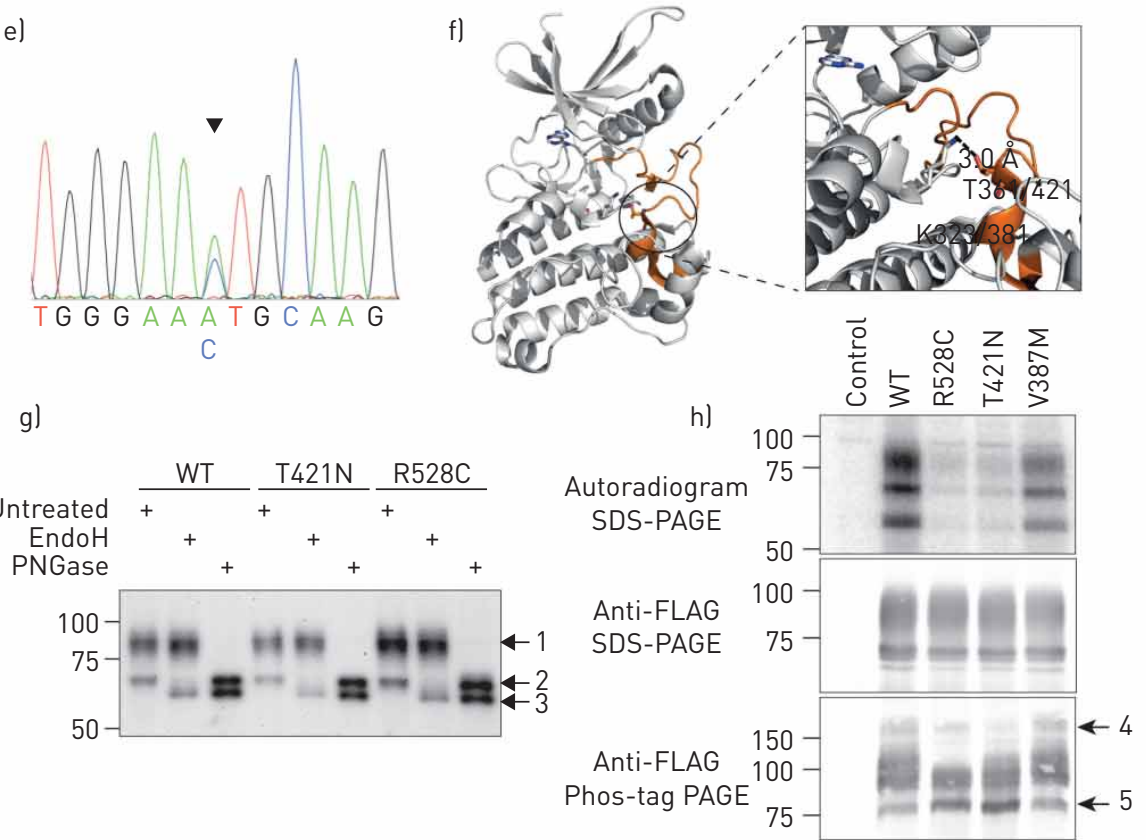

FIGURE 1 a) Chest radiograph demonstrating left apical pneumothorax. b) Photograph of patient's uvula. c) Coronal reformat of chest computed tomography (CT) (lung windows setting). Arrowheads: numerous subpleural blebs at both apices. d) Sagittal reformat of contrast-enhanced CT of thoracic aorta. Black lines shows maximal dimensions of the aortic root at the sinus of Valsalva (3.54 cm), confirmed by echocardiography, and sinotubular junction $(2.93 \mathrm{~cm})$. e) Chromatogram of sequence in the region of the c.1262C>A. Arrowhead: p.Thr421Asn mutation. f) Mutation site lenlarged in inset) modelled on crystal structure (PDB ID 2QLU) of activin receptor 2b (ActR2B). Residue numbering given in form ActR2B/ transforming growth factor- $\beta$ receptor II (TGF $\beta R$ III). The mutation site occurs within the activation loop (orange) of the molecule that is critical for regulation of substrate binding and kinase activity. Thr361/421 forms a hydrogen bond (dashed line) with Lys323/381. Its perturbation would therefore destabilise the conformational behaviour of the activation loop. g) Protein glycosylation. Endoglycosidase (Endo)H and peptide $\mathrm{N}$-glycosidase (PNGase) digestion of TGF $\beta$ RII protein. Human Embryonic Kidney (HEK)293T cells were transiently transfected with expression vectors encoding TGF $\beta$ RII proteins: wild type (WT), the new T421N mutant and a known kinase-dead mutant, R528C. Protein lysate was either left untreated or digested with EndoH or PNGase. Mature glycosylation is indicated by arrow 1, immature glycosylation (endoplasmic reticulum form) by arrow 2 and the fully deglycosylated form by arrow 3. Note the majority of each protein is resistant to EndoH digestion, indicating glycan processing within the Golgi apparatus. h) Protein autophosphorylation. HEK293T cells were transiently transfected with expression vectors encoding FLAG-tagged TGF $\beta R$ II proteins: WT, T421N, R528C and V387M. Cells were lysed and FLAG proteins purified by immunoprecipitation. After elution with FLAG peptide, one third of the material was incubated with $1 \mu \mathrm{Ci}\left[\gamma^{32} \mathrm{P}\right]$-ATP for $30 \mathrm{~min}$ at $30^{\circ} \mathrm{C}$ then separated by SDS-PAGE. Equal amounts of the remaining eluate were subjected to SDS-PAGE or Phos-tag SDS-PAGE, transferred to nitrocellulose membrane and immunoblotted for FLAG. Arrow 4 identifies a slowly migrating, phosphorylated species, while arrow 5 indicates a rapidly migrating, poorly phosphorylated species. 
widely appreciated causes: Marfan Syndrome, vascular Ehlers-Danlos syndrome, tuberous sclerosis/ lymphangioleiomyomatosis and Birt-Hogg-Dubé Syndrome [6].

Our patient's pneumothorax was treated conservatively and resolved. There have been no further pneumothoraces during the subsequent 3 years. She was commenced on losartan and propranolol as aortic protection and we continue to monitor her aortic root diameter. In conclusion, we describe a case of LDS presenting as spontaneous pneumothorax, which illustrates the growing challenges of functional validation in the genomic era, as well as enriching the phenotypic spectrum of known genetic disorders and demonstrating overlap with related disorders. http://ow.ly/SlMkS

Joseph E. Chambers ${ }^{1,4}$, Lucy E. Dalton ${ }^{1,4}$, Deepak N. Subramanian ${ }^{2,4}$, Bibek Gooptu ${ }^{3}$, Anu Balan ${ }^{2}$, Soo-Mi Park ${ }^{2}$, Simon Holden ${ }^{2}$ and Stefan J. Marciniak ${ }^{1,2}$

${ }^{1}$ Cambridge Institute for Medical Research, University of Cambridge, Cambridge, UK. ${ }^{2}$ Cambridge University Hospitals NHS Foundation Trust, Cambridge, UK. ${ }^{3}$ School of Crystallography, ISMB, Birkbeck College, University of London, London, UK. ${ }^{4}$ These authors contributed equally.

Correspondence: Stefan J. Marciniak, Cambridge Institute for Medical Research, Hills Road, Cambridge CB2 0XY, UK. E-mail:sjm20@cam.ac.uk

Received: June 172015 | Accepted after revision: Aug 242015 | First published online: Oct 222015

Support statement: S.J. Marciniak is a UK Medical Research Council Senior Clinical Fellow.

Conflict of interest: None declared.

\section{References}

1 Loeys BL, Chen J, Neptune ER, et al. A syndrome of altered cardiovascular, craniofacial, neurocognitive and skeletal development caused by mutations in TGFBR1 or TGFBR2. Nat Genet 2005; 37: 275-281.

2 Horbelt D, Guo G, Robinson PN, et al. Quantitative analysis of TGFBR2 mutations in Marfan-syndrome-related disorders suggests a correlation between phenotypic severity and Smad signaling activity. J Cell Sci 2010; 123: 4340-4350.

3 Kinoshita E, Kinoshita-Kikuta E, Koike T. Phos-tag SDS-PAGE systems for phosphorylation profiling of proteins with a wide range of molecular masses under neutral pH conditions. Proteomics 2012; 12: 192-202.

4 Iwata J, Hacia JG, Suzuki A, et al. Modulation of noncanonical TGF- $\beta$ signaling prevents cleft palate in Tgfbr2 mutant mice. J Clin Invest 2012; 122: 873-885.

5 MacCarrick G, Black JH, III, Bowdin S, et al. Loeys-Dietz syndrome: a primer for diagnosis and management. Genet Med 2014; 16: 576-587.

6 Hopkins TG, Maher ER, Reid E, et al. Recurrent pneumothorax. Lancet 2011; 377: 1624.

Eur Respir J 2015; 46: 1832-1835 | DOI: 10.1183/13993003.00952-2015 | Copyright @ERS 2015 